\title{
Improving Academic Listening Skills of Second Language by Building up Strategy Object Mashups
}

\author{
Hangyu $\mathrm{Li}^{1, *}$ and Shinobu Hasegawa ${ }^{2}$ \\ ${ }^{1}$ School of Information Science, Japan Advanced Institue of Science and Technology, \\ 1-1, Asahidai, Nomi, Ishikawa, 923-1292, Japan \\ lihangyu@jaist.ac.jp \\ ${ }^{2}$ Center for Graduate Eduation Initiative, Japan Advanced Institue of Science and Technology, \\ 1-1, Asahidai, Nomi, Ishikawa, 923-1292, Japan \\ hasegawa@jaist.ac.jp
}

\begin{abstract}
Most foreign students studying abroad lack of academic listening ability which is considered to be very important for their academic life. Among the four language activities (Reading, Listening, Speaking and Writing), the listening comprehension ability is perceived as the most difficult to improve. Therefore, the purpose of this research is to support the training of academic listening ability for the students pursuing their academic success in a foreign educational institute. Firstly, this research identifies and organizes listening strategies proved to be effective in academic listening through past researches and modulates them as sequential learning processes referred as strategy models. And then based on the various strategy models, the components of supporting functions serving as strategy objects are to be designed and developed. By putting various strategy objects together, the learners are able to build up personal learning environments (Strategy Object Mashups) based on their characteristics and conditions. At the same time, a feedback agent is to be implemented for recommending proper object mashups to the learners according to their learning situations.
\end{abstract}

Keywords: Listening Strategy, Strategy Objects, Strategy Object Mashups.

\section{Introduction}

Foreign students are faced with many challenges when pursuing academic success abroad, even after passing the language test required by their targeted educational institutes. Among the other language skills (Reading, Writing and Speaking), academic listening tasks pose serious challenges to F/SL (Foreign, Second Language) learners. Even for students with high level of proficiency and being comfortable with everyday listening and conversation, listening tasks encountered in academia still seem formidable [1]. Academic listening is complex, multi-faceted process which places enormous skill demands on the listener [2]. Since researches have shown that effective academic listening comprehension skills are essential for the students to achieve academic success [3-5], studies focusing on this subject are actively 
conducted worldwide. Among those, listening strategy is an important subject, which is playing an important part in improving academic listening skills [10]. However, students studying abroad often are faced with the difficulty of applying appropriate listening strategies for practicing their listening skills, for they study alone and lack necessary guidance from the experts. In order to address this problem, we intend to develop a learning environment which enables learners to practice their listening ability under the adaptive supporting functions according to their characteristics and learning situations. Moreover, by attaching semantic meanings (listening strategies) to the different functions used by each individual, we expect not only the awareness of strategy application to be strengthened but also the perceivable comparisons of different function use among the learners to take place, which leads to the possibility for improvement on learning skills. Therefore, unlike previous researches which provide fixed identical functions to the learners, we entitle the learners with the flexibility to build up their distinctive learning environment by putting together functional units provided, along with the self-adjustment supported by peer-reviews and system recommendation. To discuss this approach in details, the following sections are arranged like this: we firstly talk about the concept of listening strategy and the difficulties existing among F/SL learners trying to apply proper listening strategies into their practices, and then identify the limitations in recent CALL systems and the detailed purposes of this research, and finally we introduce our research method called strategy object mashups approach and describe our expectations in the end.

\section{$2 \quad$ Listening Strategy}

In cognitive psychology, the term 'strategy' is linked to the conceptual framework of human learning and memory and refers to mental steps or operations carried out to accomplish cognitive tasks. As a result, listening strategies are mental mechanisms carried out by second language learners to achieve reasonable comprehension when processing information contained in a large input of utterance, because they have to work under the constraints of an overloaded working memory, and a lack of linguistic, sociolinguistic and content knowledge [6-8]. O'Mally and Charmot (1985) categorized listening strategy into three classifications as shown in Figure 1: Metacognitive strategy, Cognitive strategy and Social strategy [9]. Generally speaking, cognitive strategies are fundamental operations taken by the learners directly on their learning subject to obtain knowledge. A learner who successfully inferred the meaning of an unfamiliar word during listening would be putting a cognitive strategy into operation. Metacognitive strategies are concerned with how to learn or with learning to learn, involving with planning, monitoring and self-evaluation combined with the learning process. The learners who take note to track their level of comprehension during listening, for example, are adopting a metacognitive strategy. Social strategies are social behaviors learners conduct when communicating with others, and examples include asking skilled ones for advises, to compare notes and etc. 


\section{Listening Strategies}

O'Malley et al.(1989) Categorized listening strategies into three classifications:

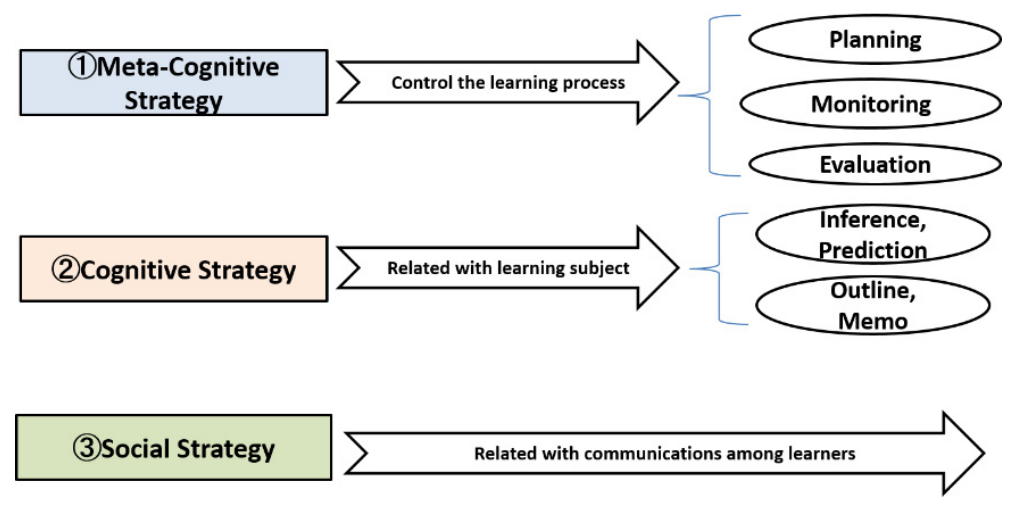

Fig. 1. Listening Strategy

Evidence from various studies revealed that L2 learners, regardless of skilled or unskilled, were all applying some listening strategies, consciously or unconsciously. The only difference lies in what they are using and the way of using them. Learners with higher listening ability tend to choose listening strategies more adaptive to their learning situations and put the chosen strategies into practice more effectively than the unskilled ones. Moreover, since what learners know about their learning can directly influence the process and even the outcome of it [10], it has been proved more than once the importance of improving learners' awareness of listening strategy through various experiments of related researches [11-12]. Goh (2008) stressed in her findings that learners need to be aware of how their listening comprehension is affected by their choice of listening strategies to develop flexibility in the use of listening strategies as well as find suitable ways for systematic practice, ultimately be able to obtain listening skills required by a successful academic life.

\section{Difficulties in Applying Listening Strategies in Academia}

Although researchers in the field of linguistics have repeatedly proven the effectiveness of consciously adopting adaptive strategies in listening practice through various methodologies, there are several difficulties for foreign students to successfully utilize proper listening strategies in most of the cases. Firstly, it is difficult to consciously put listening strategies into operation. Indeed, there are efforts having been put into teaching the techniques to insinuate the application of listening strategies [13], and the results of which were mostly positive. However, in academic life where foreign students often are pressed by hard schedule and mostly failed to attend such classes, selfdirected learning is the main approach for practicing academic listening ability. As a result, they tend to resort to their inefficient accustomed way of practicing without 
being aware of what strategies they are using and how these strategies affect their learning. Secondly, it is difficult to flexibly adopt adaptive listening strategies. Factors including personal traits, motivational level and cognitive style may influence the strategy choice [14]. Because of their lacking of strategy knowledge and guidance of strategy application, it is difficult to come up with an adaptive combination of listening strategies which suits the learners' characteristics and their learning goals. Thirdly, it is difficult to put social strategies into practice. As for self-directed learning is the mainstream among foreign students to build up the necessary skills of the targeted language, it is considered inconvenient for them to get involved actively in communication or cooperation with like-minded people to ask help, exchange ideas and get advices. This leads to the missing of learning chances and sharing of knowledge.

\section{$4 \quad$ Limitations in Current CALLs and Research Purposes}

While researchers of the educational linguistics are focusing on the pedagogy for improving language skills, there are also attentions being drawn in the development of CALL system. The original definition of CALL are covering a wide range of computer systems as long as involved with the keywords 'computer' and 'language learning'. Since the focus of this research is to help learners cultivate necessary academic listening skills through self-directed learning. We narrowed the definition of CALL to mean self-guided learning support system which the learners work through at their own pace in a self-directed way. Back in the late 80's, and early 90's, with the fast development of information technologies and the prevailing use of computer, CALL was breaking ground in the new technology frontier and began to draw attentions. Up to now, numerous CALL systems have been developed to meet different requirements, most of those are working as an additional supplementary to actual teaching courses known as blended learning [15]. Therefore, most of these systems are not designed for self-directed learning and proved performing better only combined with the involvement of the instructors. Among those CALLs appropriate to be used in a self-directed way, though only a few of which are for training listening skills [16], there are some limitations. First of all, they failed to improve learners' metacognitive awareness of learning strategies. The current CALLs mainly focus on providing the users with a set of pre-designed functions without making the users aware of the according strategy applications which are meant to help them perform better. Secondly, they failed to offer adaptive supporting functions for different learners. Recently, there are some adaptations being considered in terms of providing diverse training materials [17], however, learners are not in the position of choosing or adjusting system functions to meet their learning goals. Thirdly, they are not providing enough support to integrate social strategies, which causes the lack of communication among learners. Although there are CALLs enabling limited sharing and peer-reviews on learning outcomes [18], the learning skills of each learner and the strategy application are difficult to represent in a recognizable way. Considering these limitations existing in current CALL systems, and in order to address the difficulties encountered by foreign students in an attempt to improve their academic listening ability, this research 
aims to design and develop a self-directed and community-based learning environment with the main purposes of: making learners aware of strategy application, helping them build up adaptive learning environments, and enabling them to communicate on not only leaning resources and knowledge but also learning strategies and techniques. We expect the learners to learn and improve their learning skills through: the strengthened awareness of their strategy application; the process of building up their adaptive learning environments which are constantly adjusted by themselves from peer-reviews and system recommendation; and the awareness of the connections between their learning activities and the according listening strategy.

\section{$5 \quad$ Strategy Object Mashups Approach}

Before getting into details of this approach, we need to understand the concept of comprehension tactics (which is referred as tactics in this paper) brought up by Goh (1998) [10]. She defined tactics as individual mental techniques through which a general strategy is operationalized. Goh also identified that the tactics used for the same strategies vary from learner to learner, and skilled learners demonstrated better on strategy choices and the combination of appropriate tactics. For example, a learner successfully inferred the meaning of an unfamiliar word by the hints received from earlier utterance; on the contrary, another learner inferred by referring to his own world knowledge combined with the current context. The fact is that they are adopting the same cognitive strategy called inference but through different tactics. The reasons for this difference, Goh indicated, may exist in the learners' differences in listening ability or whether being aware of strategy use, which we think could open up the possibility for interactions and communications on learning skills among learners of different level by comparing tactics use with each other. Since one of the purpose of this research is to improve the awareness of strategy application, the tactics through which strategies are being conducted by the learners indirectly, become a very important issue. As the tactics are in fact metal techniques taken by the learners when trying to extract meaning from an utterance, the learners are considered to be under great cognitive overload. In order to address this problem, this research will externalize the common tactics in the form of computer-assisted functions while building connections with the corresponding listening strategies, expecting not only the cognitive overload to be alleviated but also, the awareness of strategy adoption to be strengthened. In addition, we also expect the tactics adopted by each learner will be recognizable so that the communications on learning techniques can also take place.

This research firstly organizes related strategies revealed in the past researches positively applicable for cultivating academic listening ability and then, based on which, design and develop a learning environment providing adaptive supporting functions to different learners based on their features and learning situations. Figure 2 describes the concept of this approach. After identifying the related listening strategies, the tactics commonly adopted to operate those strategies will also be sought and organized to systematize respective learning strategy models. And then, the identified models will be visualized in term of various functional units as strategy objects in the 
system, from which the learners can choose to construct their personal assembly of the functional units as strategy object mashups. Finally, we will also construct a communication platform to not only support the communication activities on learning knowledge and resources, but also on strategy object mashups which we would like to consider as a sort of communication on learning techniques. At the same time, an agent collecting and analyzing all mashups created by everyone will be developed to recommend the learners with more appropriate strategy objects for adjustment according to their features and learning situations. The following sections will explain this approach in details.

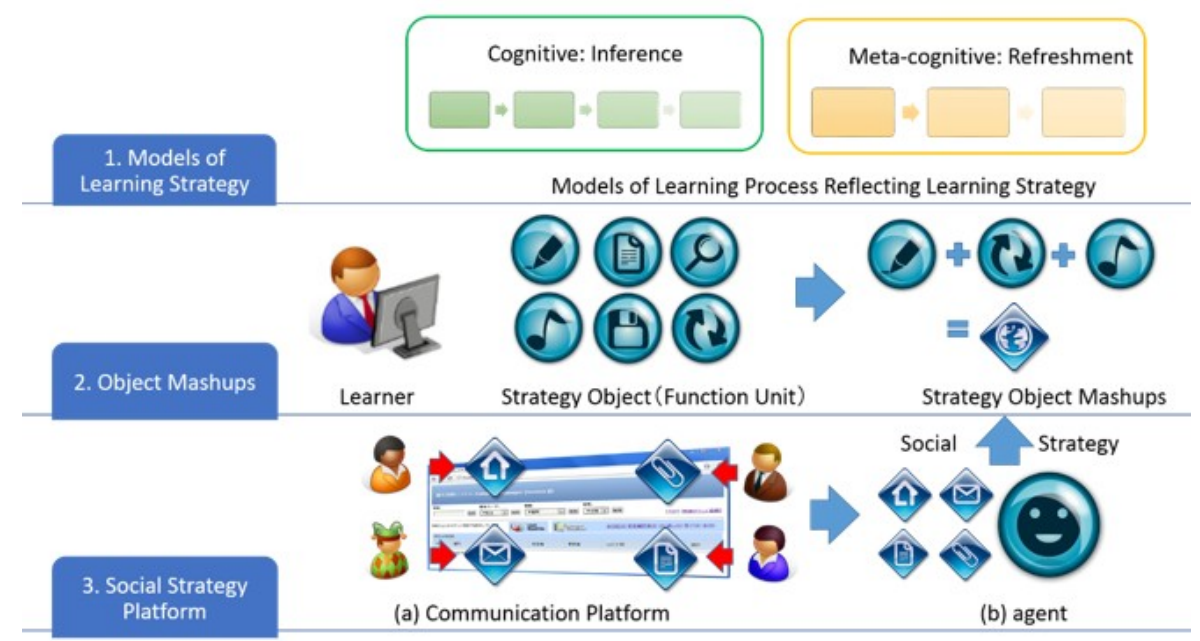

Fig. 2. The Concept of Strategy Object Mashups Approach

\subsection{Learning Strategy Model and Strategy Object}

The existing listening strategies are too abstract to be represented on a computer screen. However, the comprehension tactics serving as media to the according strategies, on the other hand, are understandable mental behaviors possible to be visualized as operable computer functions. For this reason, we firstly will identify and organize comprehension tactics proved to be effective in academic listening, and then modulate these tactics as sequential learning processes. Meanwhile, these tactics are corresponded to the according listening strategies in an ontological manner under the classifications of meta-cognitive, cognitive and social strategies defined by O'Mally (1985) [9]. The strategy models are expected not only to be able to represent the learning processes of different learners using distinctive tactics under the same learning strategy, but also to be presented as the model of the intellectual activities with the applicable description for designing purpose. Secondly, based on various strategy models, the components of supporting functions serving as strategy objects will be designed and developed. Figure 3 depicts the concept of strategy object and how it relates to the strategy models. In this figure, there is a typical cognitive strategy called inference. 
Three comprehension tactics, for example are identified to operate this strategy: inference from related background knowledge, inference from other people's comments (this tactic also relates to the social strategy of cooperation), and inference from the related pictures. When trying to functionalize these tactics, it is possible to develop functional units such as: display comments of others, display background knowledge, display pictures and input keywords. These functional units are referred as the strategy objects from this research point of view.

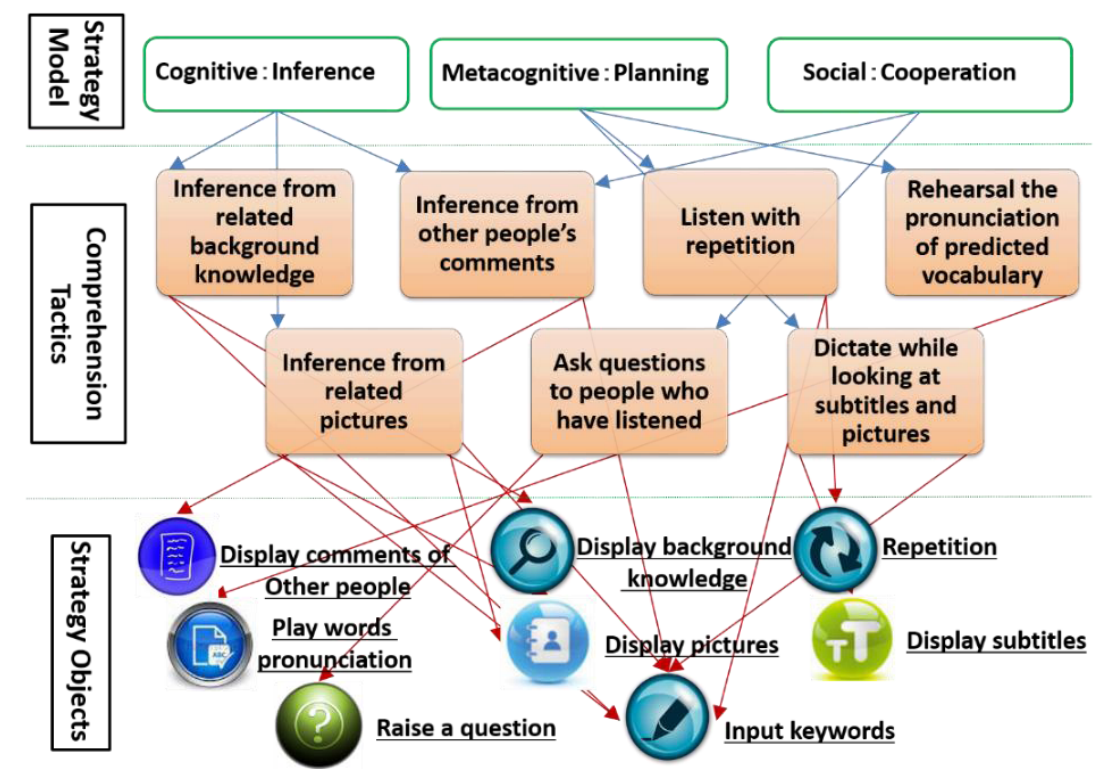

Fig. 3. Concept of Strategy Object

\subsection{Construction for Adaptive Learning Environment through Building up Strategy Object Mashups}

Unlike the existing CALL system providing only determined supporting functions, this system is expected to provide the learners with different listening ability and personal traits with adaptive training environment by enabling them to select and assembly strategy objects to compose their personal supporting functions as the process of building up strategy object mashups. As described in Figure 4, the strategy objects illustrated in Figure 3 are for choosing by self-directed learners. Supposedly one of the learners in the graph picked the objects of display comments of other people, display background knowledge and input keywords, the chosen three objects are working together as object mashups to support his learning activity. In this way, by tracing the comprehension tactics related with the chosen objects, a new tactic (inference from related background knowledge and comments of others and input keywords) is generated and so does its relationship with the corresponding strategies, which combined with the learner's features and learning situation will be analysed and stored by 
the system as a latest addition to strategy models, aiming to recommend proper strategy objects to learners for adjustment of their strategy mashups. During the process of building up personal strategy mashup, we expect them to improve their listening skills by practicing with adaptive supporting functions, while reminding them of what strategies and tactics are being used to improve their awareness of strategy application.

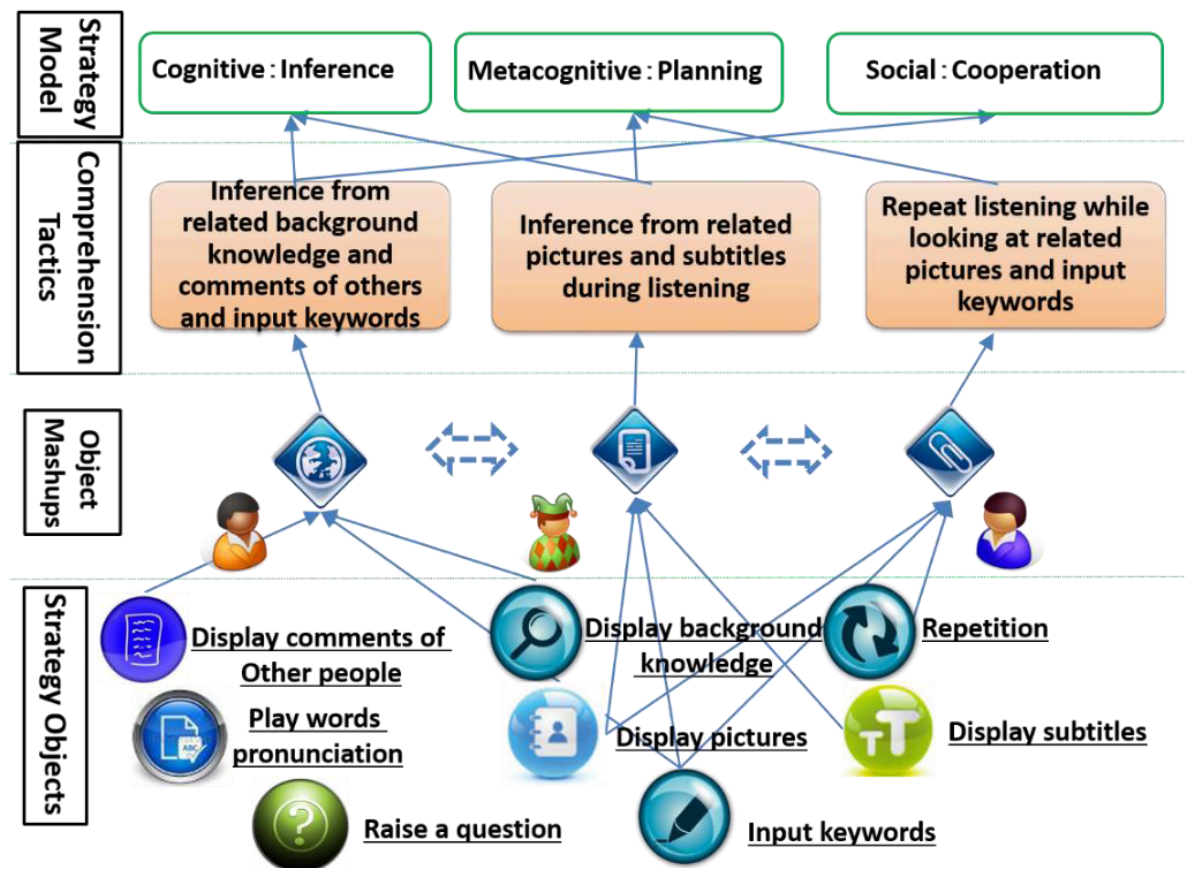

Fig. 4. Concept of Strategy Object Mashups

\subsection{Social Strategy Platform and Feedback Agent}

Since social strategy is playing an important role in improving academic listening ability, it is necessary for this research to combine a communication platform properly with the self-directed learning environment we intend to develop. On this platform, not only the knowledge and learning resources will be shared, but also the strategy object mashups created by each individual. Along with the comparison with the mashups of other learners, the self-adjustment of one's mashups becomes possible and the awareness of using related tactics and listening strategies is expected to be strengthened.

In order to support one's self-directed learning, providing feedbacks on one's learning process also seems to be desired. A feedback agent, as another aspect of this research, will be used to recommend proper object mashups to learners based on the analysis of their choice of the strategy objects combined with their learning situation. 


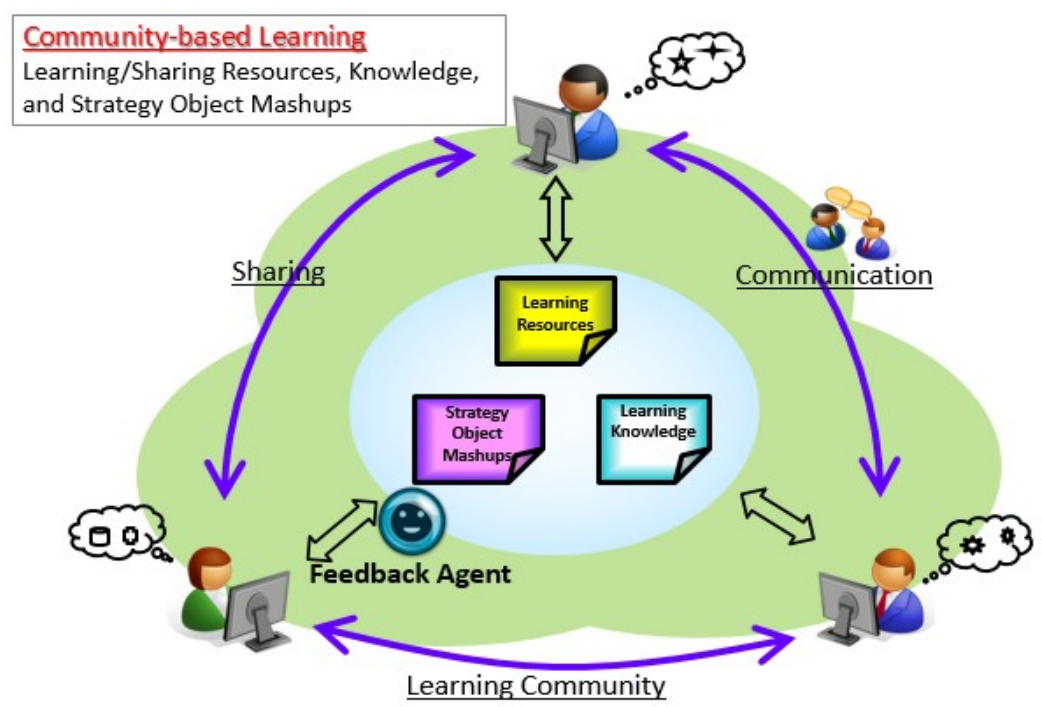

Fig. 5. Social Strategy Platform

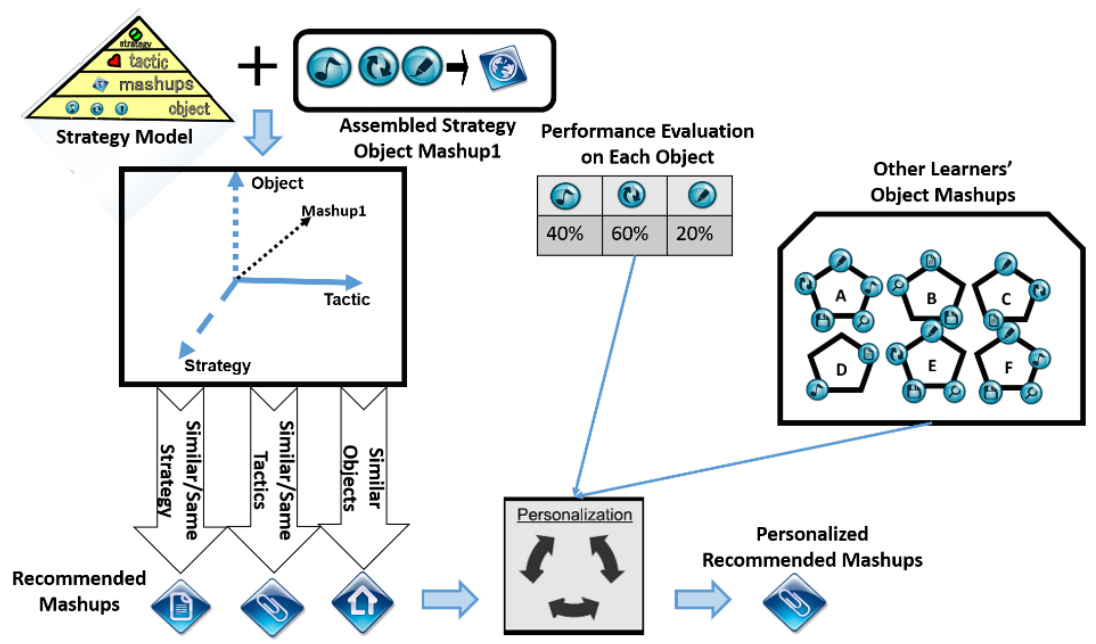

Fig. 6. Mechanism of the Feedback Agent

The Figure 6 describes the mechanism of the feedback agent. Firstly, it analyzes the current object mashup by referring to the corresponding strategy model and then maps the mashup to a proper position in the axis of object, tactic and strategy. After this, the agent provides several candidates of strategy mashups by following the roles of similar/same strategy, similar/same tactics, and similar objects compared with the current mashup. The next stage is to filter the candidates of recommended mashups for 
personalization by evaluating learner's performance on each selected object (such as counting the number of written keywords) to decide which object suits the learner better and which not, along with the comparison with the mashups adopted by the other learners of similar level and their performance on the chosen object. Finally the feedback agent will provide the learners with the best choices of mashups for their self-adjustment. In this way, we believe that, on the system, the learners will be able to adjust their object mashups through system recommendation and comparison with the others, as a result gradually build up their learning skills in the process

\section{$5.4 \quad$ Multi-layer Model}

Figure 7 summarizes what has been discussed so far as the model of this research. It shows a multi-layer model which possesses of four layers. The object layer is where the system presents all the strategy objects for the learners to choose and assemble. Also, the detailed description of each object will also be provided to the learners to help them make reasonable choices. The learners choose their wanted objects and the system assembles the selected ones into strategy object mashups on the upper layer where, basically, the learners conduct their listening practice supported by their object mashups while referring to the mashups of others if necessary. The tactic layer is where to generate new tactics based on the learners' object mashups, by putting together the tactics originated from the selected objects. And accordingly, the listening strategy related to the newly created tactics can be found on the strategy layer. The upper two layers are meant to attach semantic meanings to the functional units (object mashups) being used by the learners, with the purpose of improving their awareness of what listening strategies and tactics are being used and how they affect their learning in order to improve their listening skills. The connections between layers are to be stored and analyzed by the feedback agent for the proper recommendation of the object mashups for the learner. Therefore, by using the proposed system, the learners

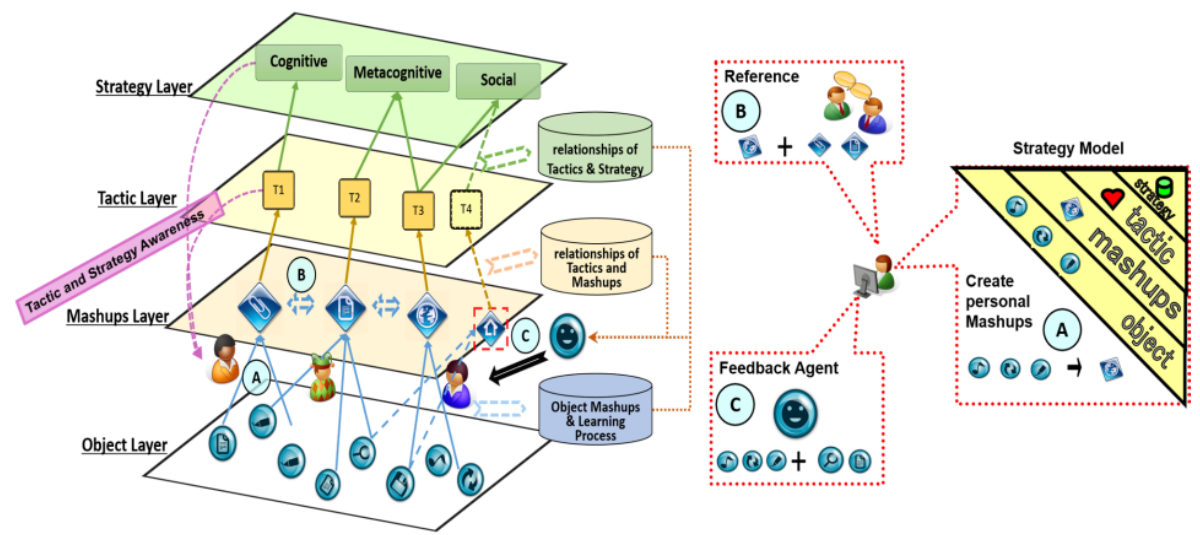

Fig. 7. Multi-layer Model 
would be able to assemble their personal object mashups by putting together proper objects, to refer to others' object mashups for possible adjustment of their own, and to take into account of system's recommendation of new object mashups which could be more effective. We hope during the process of building up their personal object mashups while being made aware of the corresponding strategy and tactic use, the learners could learn and improve effective learning skills along the way.

\section{Conclusion and Future Work}

This paper has proposed a learning environment where the learners not only are able to construct adaptive supporting functions by putting together wanted strategy objects, but also to be aware of the corresponding comprehension tactics and listening strategies they are adopting and how are they affecting their learning with the purpose of improving their listening skills. Moreover, on the proposed platform, the learners are expected to learn through building up object mashups which can be flexibly adjusted by the comparisons with that of others' and the recommendation from the system. We believe this research might open the possibility of providing an adaptive learning environment to diverse learners and a more recognizable format for reference and communication on learning skills in a virtual place.

In the near future, we firstly will identify several useful listening comprehension tactics from related researches and start constructing a few strategy models. Based on these models, the according strategy objects will be designed and developed, so as the mashups environment as web services using Microsoft ASP.NET MVC. After finishing the pilot system, an evaluation will be conducted to firstly make sure whether the learning effectiveness can be improved through building up object mashups, and secondly whether the adjustment of mashups useful from peer comparisons and system recommendation.

\section{References}

1. Mason, A.: By dint of: Student and lecture perceptions of lecture comprehension strategies in first term graduate study. In: Flowerdew, J. (ed.) Academic listening: Research perspectives, pp. 199-218. Cambridge University Press, Cambridge (1995)

2. Richards, J.: Listening comprehension: Approach, design, procedure. TESOL Quarterly, vol. 17, pp. 219-239. Teachers of English to Speakers of Other language, Inc. (1983)

3. Benson, M.J.: Lecture listening in an ethnographic perspective. In: Flowerdew, J. (ed.) Academic listening: Research perspectives, pp. 181-198. Cambridge University Press, Cambridge (1994)

4. Dunkel, P.: Listening in the Native and Second/Foreign Language: Toward an Integration of Research and Practice. TESOL Quarterly, vol. 25(3), pp. 431-457. Teachers of English to Speakers of Other Language, Inc. (1991)

5. Vandergrifft, L.: Listening to learn or learning to listen. Annual Review of Applied Linguistics, vol. 24(3-25). Cambridge University Press, Cambridge (2004) 
6. Call, E.: Auditory short term memory, listening comprehension and the Input Hypothesis. TESOL Quarterly, vol. 19(4), pp. 765-781. Teachers of English to Speakers of Other Language, Inc. (1985)

7. Farch, C., Kasper, G.: The role of comprehension in second language learning. Applied Linguistics 7, 257-274 (1986)

8. Goh, C.C.M.: A cognitive perspective on language learners' listening comprehension problems. System 28(1), 55-75 (2000)

9. O'Mally, J.A.: Listening Comprehension Strategies in Second Language Acquisition. Applied Linguistics 10(4), 418-437 (1989)

10. Goh, C.C.M.: How ESL learners with different listening abilities use comprehension strategies and tactics. Language Teaching Research 2(2), 124-147 (1998)

11. Goh, C.C.M.: Metacognitive Instruction for Second Language Listening Development: Theory, Practice and Research Implications. RECL Journal 39(2), 188-213 (2008), SAGE Publications, Los Angeles, London, New Deli and Singapore (2008)

12. Holden, R.: Facilitating Listening Comprehension: Acquiring Successful Strategies, vol. 28, pp. 257-266. Bulletin of Hokuriku University, Japan (2004)

13. Hossein, B.: Enhancing foreign language learning through listening strategies delivered in L1: An Experiment Study. International Journal of Instruction 5(1) (2013)

14. Oxford, R., Nyikos, M.: Variables Affecting Choice of Language learning Strategies by University Students. The Modern Language Journal 73(3), 291-300 (1989)

15. Wikipedia: Blended Learning, http://en.wikipedia.org/wiki/Blended_learning

16. Smidt, E., Hegelheimer, V.: Effects of online academic lectures on ESL listening comprehension, incidental vocabulary, and strategy use. Computer Assisted Language Learning 17, 517-556 (2004)

17. Wang, J., Mendori, T.: An Evaluation of a Customizable Ontology-driven Language Learning Support System. In: 21st International Conference on Computers in Education, pp. 11-19. Asia-Pacific Society for Computer in Education, Indonesia (2012)

18. Ogata, H., Yano, Y.: Knowledge awareness for a computer-assisted language learning using handhelds. International Journal of Continuing Engineering Education and Life Long Learning 14, 435-449 (2004) 